\title{
BEHAVIOR OF LARGE-SCALE BRACING SYSTEM IN TALL BUILDINGS SUBJECTED TO EARTHQUAKE LOADS
}

\author{
Ali Hemmati ${ }^{1}$, Ali Kheyroddin ${ }^{2}$ \\ Faculty of Civil Engineering, Semnan University, Semnan Province, Iran \\ E-mails: ${ }^{1}$ ahemmati2000@yahoo.com (corresponding author); ${ }^{2}$ akheirodin@semnan.ac.ir \\ Received 04 May 2011; accepted 04 Jul. 2011
}

\begin{abstract}
Bracing is a highly efficient and economical method of resisting of lateral forces in a steel structure. The most common types of bracing are those that form a fully triangulated vertical truss. These include the concentric and eccentric braced types. In high-rise buildings, the location and number of bracings is an important limitation to the architectural plan. A similar scheme has been used in larger scale spanning multiple stories and bays in tall buildings which is called large-scale bracing system. Large-scale bracing (LSB) is a particular form of a space truss. It consists of multiple diagonal elements that form a diagonal grid on the face of the structure. In this paper, a 20 story steel frame with different arrangement of bracing systems is analyzed. Linear and static nonlinear (push-over) analyses are carried out and the results presented here. Analytical results show that, the large-scale bracing is more adequate system under the lateral loads. Using LSB in tall buildings, decreases the lateral displacement, drift ratio, uplift forces in foundation and increases the ductility and shear absorption percent of the bracing system. Moreover, the stress ratios in the structural members of LSB system are less than the relevant values in other bracing systems.

Keywords: large-scale bracing, tall buildings, drift ratio, Push-over analysis.

Reference to this paper should be made as follows: Hemmati, A.; Kheyroddin, A. 2013. Behavior of large-scale bracing system in tall buildings subjected to earthquake loads, Journal of Civil Engineering and Management 19(2): 206-216.
\end{abstract}

\section{Introduction}

A braced frame is an efficient structural form for resisting lateral loads. It acts as a vertical truss, with the columns as chords and the braces and girders as web members. The most efficient and conventional type of bracing, using full diagonals, is also the most obstructive to architectural plan. Other arrangements are available that are more amenable to allowing openings, but that are less stiff horizontally. The efficiency of bracing in being able to produce a laterally high stiffness for a minimum of additional material makes it an economic structural system for any height of building. A major disadvantage of diagonal bracing (conventional bracing) is that the diagonal connections are expensive to fabricate and erect, uplift in columns and low ductility (Stafford Smith, Coull 1991). Bracing system is categorized in 3 parts i.e. concentric bracing, eccentric bracing and special bracing systems (Mazzolani et al. 2009).

The traditional use of bracing has been in storyheight, bay-width modules that are fully concealed in the finished building. External large-scale bracing, extending over many stories and bays has been used to produce not only highly efficient structures, but aesthetically attractive buildings. Large-scale bracing system is an example of special bracing that is investigated in this paper. Over the last years the effectiveness of bracings in resisting lateral loading systems has been further exploited by using it on larger modular scale, both within the building and externally across the faces. In the latter form the massive diagonals have sometimes been emphasized as an architectural feature of the façade. The role of the bracing is multi purpose in resisting the horizontal shear, reducing the shear lag in the flange column axial forces and hence making the whole cross section of the building structure stiffer against lateral load bending and helping to equalize the gravity load stresses in the column (Tang, Yin 2007).

Large-scale bracing (LSB) system is a particular form of space truss. It consists of multiple diagonal elements that form a diagonal grid on the face of the building. The diagonal grid makes the structure stable even without any vertical columns. The 13 story IBM Building in Pittsburg that was completed in 1963, is an early example of such system. Recently, more buildings with LSB system has been proposed and designed. The booming trend is the result of improvements in technology and manufacturing techniques that allow for more automated fabrication. Shaking table test on 


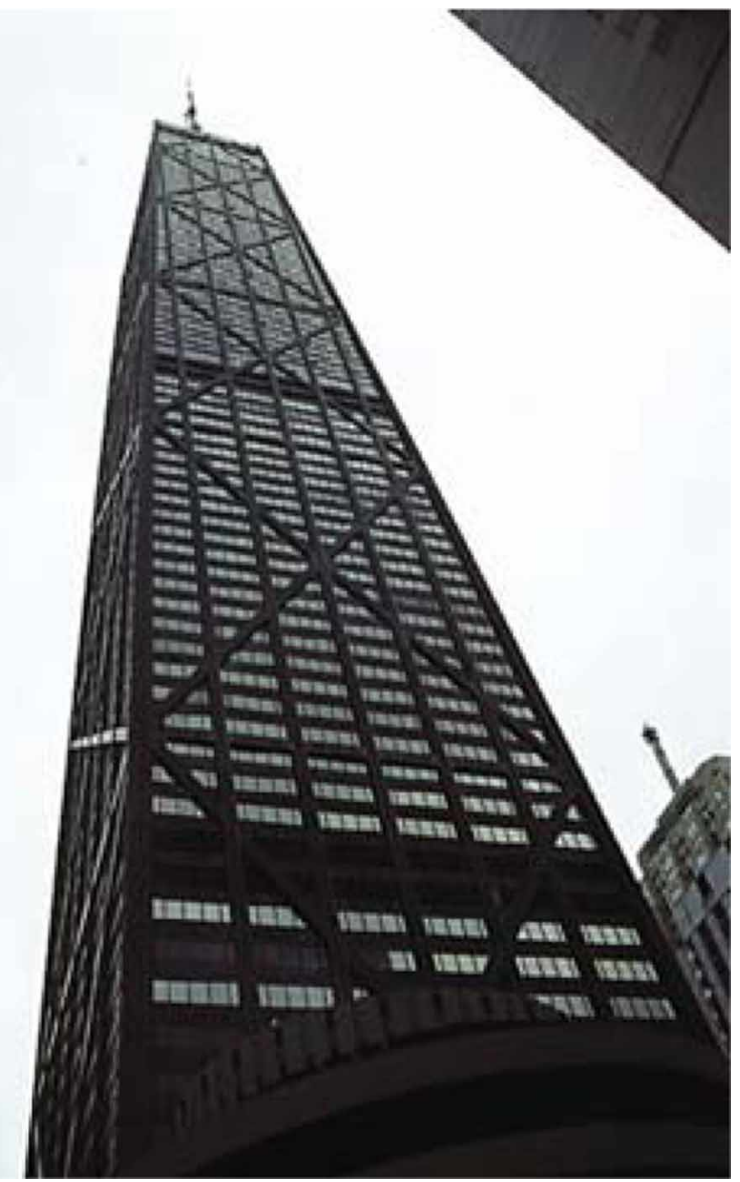

Fig. 1. The use of LSB system in John Hancock, Chicago (Leonard 2007)

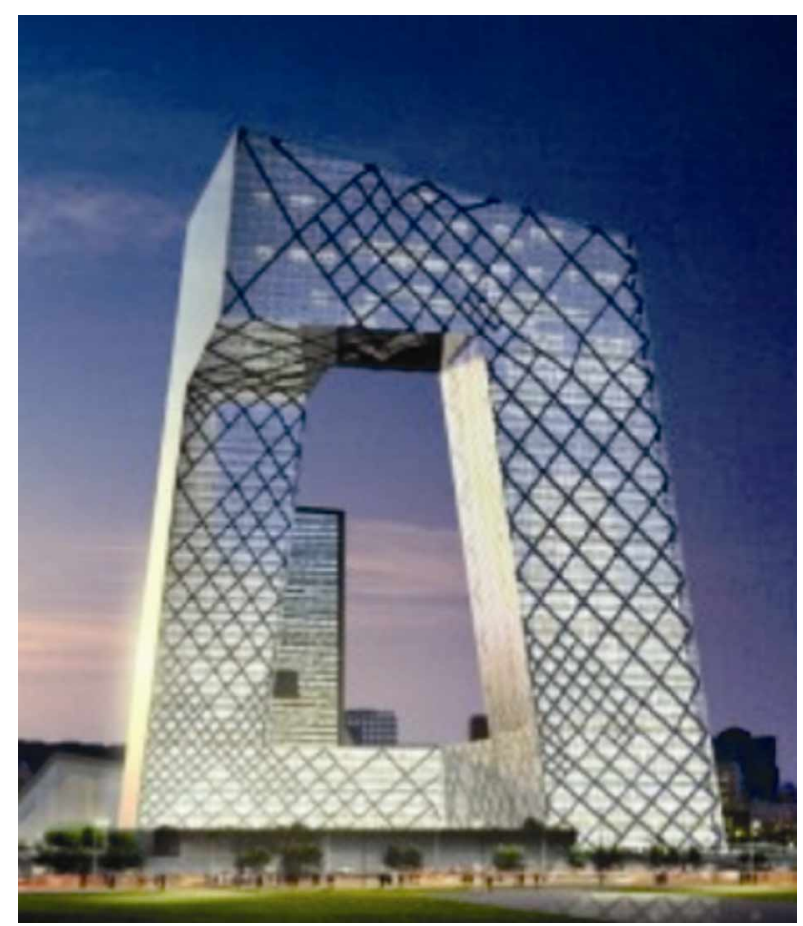

Fig. 2. The use of LSB system in CCTV Headquarters, Beijing (Leonard 2007) model of shanghai world financial center tower carried out and it showed a good behavior (Lu et al. 2007).

The John Hancock building is one of the most famous LSB systems in the world which is shown in Fig. 1 (Leonard 2007). This tall building has an exterior-braced frame tube structure. A saving of $\$ 15 \mathrm{~m}$ was made on the conventional steel work by using these huge bracings. It was regarded as an extremely economical design which achieved the required stiffness to make the giant stable. One of the reasons for the success was that the direct force path was archived by using the cross-braces, which resulted in a stiffer structure and smaller internal forces (Ji 2003). The new headquarters for Central China Television (CCTV) by Rem Koolhass of OMA is a good instance of utilization of LSB system efficiency to support building with challenging shapes (Fig. 2). Probably, the most famous examples of LSB

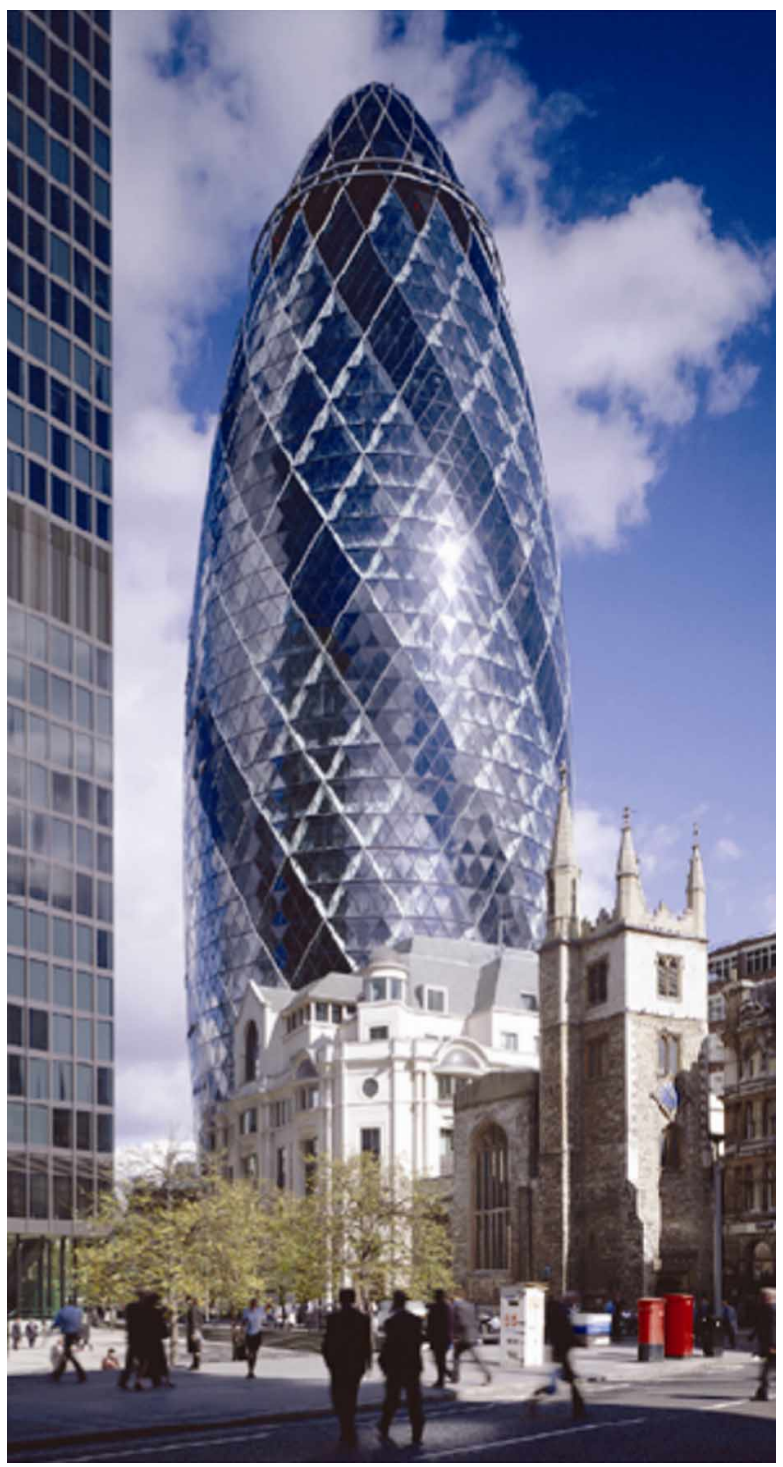

Fig. 3. The use of LSB system in Swiss Re, London (Leonard 2007) 


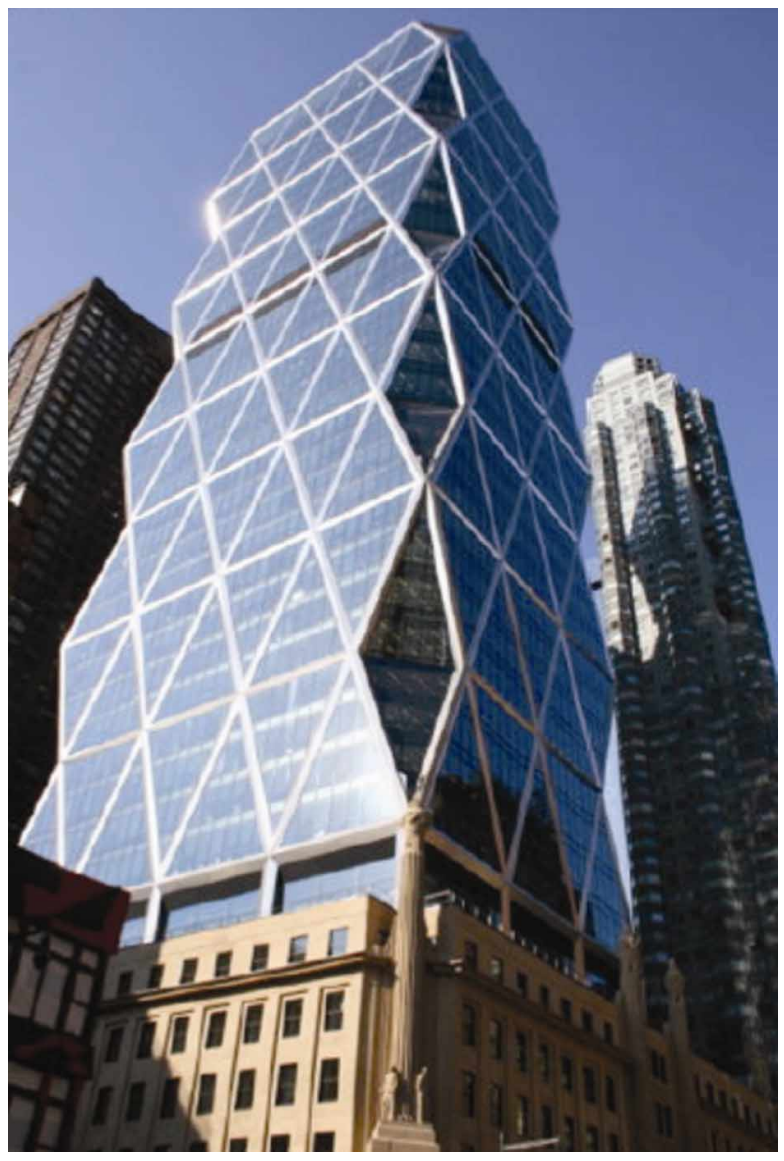

Fig. 4. The use of LSB system in Hearst Tower, New York (Leonard 2007)

buildings are the Swiss Re (2004) in London and Hearst Tower (2006) in New York which are shown in Figs 3 and 4 (Leonard 2007).

LSB system has bold appearance. It is distinctive and easily recognized. If this is the intent of the architect, LSB as a structural system provides additional aesthetic values to the building itself. This system also allows for the building to have no corner columns or even free column façade. The configuration and efficiency of LSB system reduce the number of structural element required on the façade of the building, therefore present less obstruction to the outside view. The structural efficiency of this system, also makes interior columns unnecessary, therefore, allows much flexibility on the floor plan in compared with conventional bracing system. Analytical results have been shown that tube-type structures with LSB system have high capacity against progressive collapse (Kim, Lee 2010).

A large amount of angles could be used in LSB systems. Analytical results have shown that, for 60 story LSB buildings with corner columns, the optimum angle lies between $53^{\circ}$ and $76^{\circ}$. Without corner columns, the optimum angle lays around $70^{\circ}$. In addition to, the optimum angle reduces as the number of story decreases (Moon 2005).
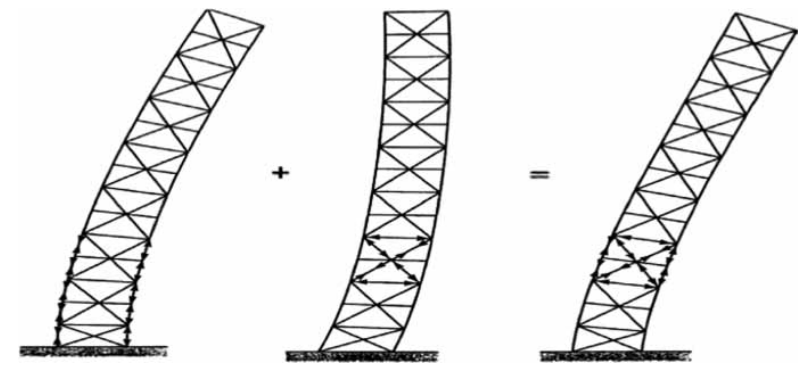

Fig. 5. Braced frame deformation (Taranath 2005)

\section{Behavior of different bracing systems}

In simple terms, in braced frames, the columns act as the chords in resisting the overturning moment, with tension in the windward column and compression in the leeward column. The diagonals work as the web members resisting the horizontal shear in axial compression or tension, depending on the direction of inclination. The beams act axially, when the system is a fully triangulated truss. They undergo bending only when the braces are eccentrically connected to them. The effect of axial deformation of the columns results in a "flexural" configuration of the deflection with concavity downwind and a maximum slope at the top. The axial deformations of the web members, on the other hand, cause a "shear" configuration of deflection with concavity upwind, a maximum slope at the base, and a zero slope at the top. The resulting deflected shape of the frame is a combination of the effects of the flexural and shear curves, with a resultant configuration depending on their relative magnitudes, as determined mainly by the type of bracing (Fig. 5). Nevertheless, it is the flexural deflection that most often dominates the deflection characteristics (Taranath 2005).

The role of web members in resisting shear can be demonstrated by following the path of the horizontal shear down the braced bent. In Fig. 6a, the diagonal in each story is in compression, causing the beams to be in axial tension; therefore, the shortening of the diagonal and extension of the beams gives rise to the shear deformation of the bent. In Fig. 6b, the forces in the braces connecting to each beam-end are in equilibrium horizontally with the beam carrying

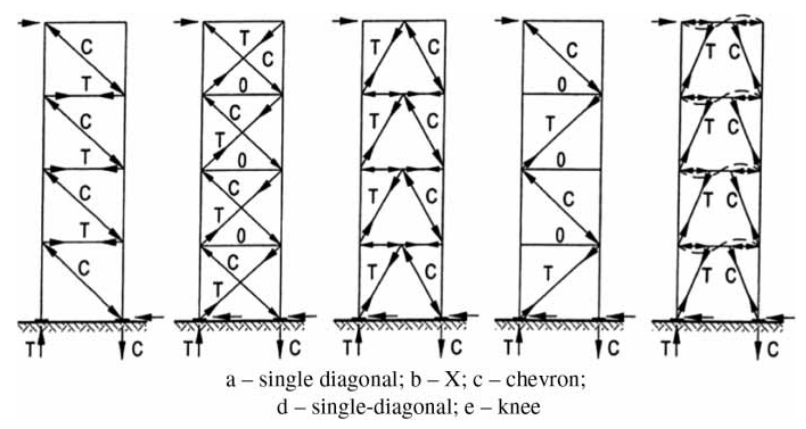

Fig. 6. Load path for horizontal shear through web members of CBF systems (Taranath 2005) 
insignificant axial load. In Fig. 6c, half of each beam is in compression while the other half is in tension. In Fig. 6d, the braces are alternately in compression and tension while the beams remain basically unstressed. Finally, in Fig. 6e, the end parts of the beam are in compression and tension with the entire beam subjected to double curvature bending. Observe that with a reversal in the direction of horizontal load, all actions and deformations in each member will also be reversed (Taranath 2005).

In a braced frame, the principal function of web members is to resist the horizontal shear forces. However, depending on their configuration of the bracing, the web members may pick up substantial compressive forces as the columns shorten vertically under gravity loads. As shown in Fig. 7a and 7b, the columns shorten, the diagonals are subjected to compression forces because the beams at each end of the braces are effective in resisting the horizontal component of the compressive forces in the diagonal. At first glance, this may appear to be the case for the frame shown in Fig. 7c. However, the diagonal shown in Fig. 7c will not attract significant gravity forces because there is no triangulation at the ends of beams where the diagonals are not connected (nodes A and $\mathrm{D}$, in Fig. 7c). The only horizontal restraint at the end is by the bending resistance of columns, which usually is of minor significance in the overall behavior. Similarly, in Fig. 7d, the vertical restraint from the bending stiffness of the beam is not large; therefore, as in the previous case, the braces experience only negligible gravity forces (Taranath 2005).

In LSB systems, under the action of gravity loading, if the diagonals are initially disconnected from the intermediate columns, the connection points on the intermediate columns will displace downward by more than the corresponding points on the diagonals, whose displacements are controlled by the vertical displacements of the less highly stressed corner columns. Hence, the diagonal members must be in compression while the spandrel beams are in tension. It is shown in Fig. 8a. If the diagonals and intermediate columns are connected together, the initial compressive force in each intermediate column is partially relieved by the upward force required at
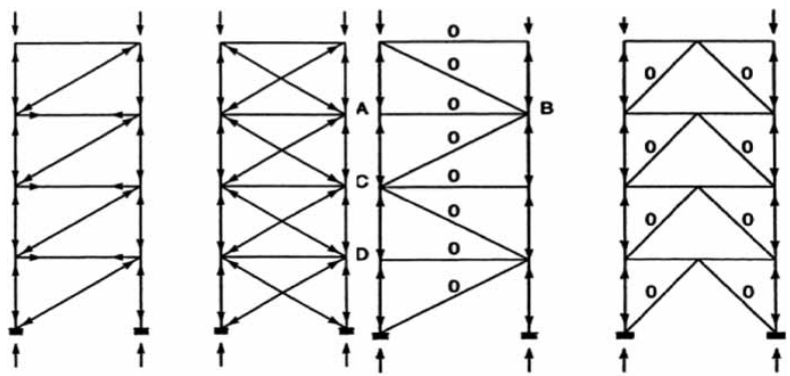

$\mathrm{a}$ - single diagonal; $\mathrm{b}$ - X; c-single-diagonal; $\mathrm{d}$ - chevron

Fig. 7. Gravity load path in CBF systems (Taranath 2005) each of its intersections with a diagonal. The corresponding down ward forces on each diagonal are carried at its ends by the corner columns, whose compressive forces are increased at each intersection with a diagonal, it is shown in Fig. 8b. Consequently, these actions reduce the initial tension in the spandrels in the upper halves of the bracing diamonds and increase the tension in lower halves. The forces in both intermediate and corner columns will change significantly at each diagonal inter-section point. Over the vertical lengths between intersection points, changes will occur only by the increment of gravity load added at each floor level. The resulting force action in the façade panel is summarized qualitatively in Fig. 9.

In LSB systems, under the action of lateral loading, if the diagonals are initially disconnected from the intermediate columns, the columns and diagonals of the face will be in tension while the spandrels are in compression. It is shown in Fig. 10a. If the diagonals and intermediate columns are connected together, interactive vertical forces will be
Gravity loading

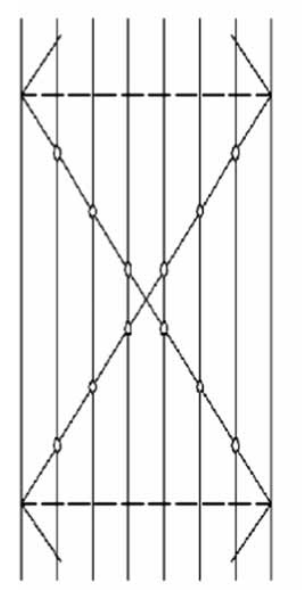

$\mathrm{a}-$ disconnected

Members in compression

\section{Gravity loading}

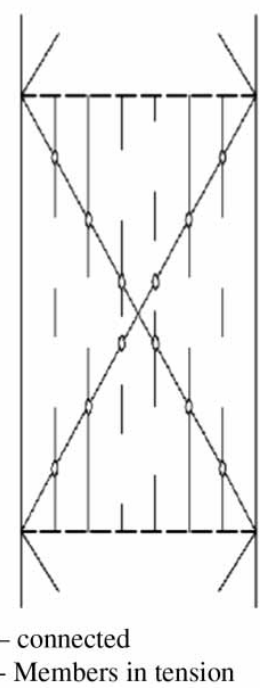

Fig. 8. Gravity load path in LSB systems (Stafford Smith, Coull 1991)

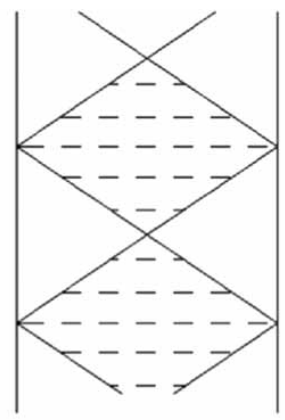

_ Members in compression - - - - Members in tension

Fig. 9. Resulting forces in LSB systems due to gravity loads (Stafford Smith, Coull 1991) 


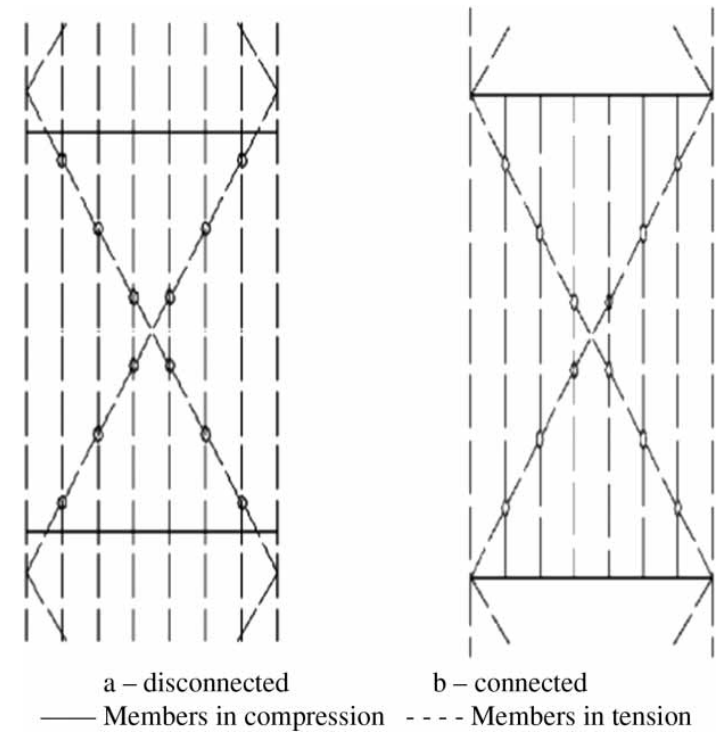

Fig. 10. Lateral load path in LSB systems (Stafford Smith, Coull 1991)

mobilized, which will pull up on the intermediate columns and down on the diagonals in order to establish compatibility at the connections. It is shown in Fig. 10b. These upward forces cause an increase in tension in the intermediate columns, while the downward increments acting on the diagonals are transferred at their ends to the corner columns, thereby; reducing the higher tensile forces that initially existed. In this way the stresses in the corner and intermediate columns, again tend to be equalized. When superimposed on the original large tensile force in the diagonal, the increments of axial force acting down the diagonal produce a gradually reducing tension along the member, leading to a small net compression in the lowest one or two panels. A qualitative representation of the net forces in the windward face due to lateral loads is shown in Fig. 11 (Stafford Smith, Coull 1991).

The forces in the columns, diagonals and spandrels on the leeward face due to the lateral loading will be opposite in sense to those on the windward face.

Among all structural forms tube systems, that has been invented by Fazlur R. Khan, offers an

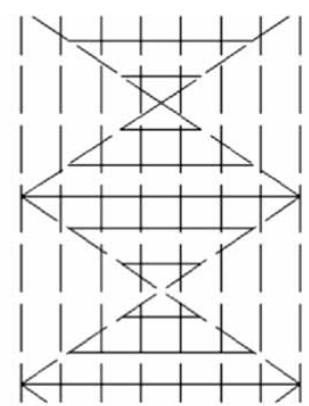

— Members in compression - - - - Members in tension

Fig. 11. Resulting forces in LSB systems due to lateral loads (Stafford Smith, Coull 1991) efficient structural system appropriate for tall buildings. Owing to this fact that, perimeter columns which are spaced closely and fastening by deep spandrels resist entire lateral loads, considerable freedom in architectural planning of interior space as well as great structural stiffness is available. The main weakness of tube structures is a phenomenon called shear lag. Shear lag causes the axial forces to distribute differently in columns than ideal distribution. This main weakness of tube structures decreases economical efficiency which is mainly caused by decreases in resistance moment of whole structure (Stafford Smith, Coull 1991).

One way to decrease the shear lag in frame-tube structures is increasing the rigidity of the spandrels beam by decreasing the column space. Contrary to what one may expect, even for a solid-wall tube, the distribution of axial forces is not uniform over the windward and leeward walls. This fact is consequent of the shear deformation of the tube walls which are relatively thin as compared to the height and plan dimensions of the building (Taranath 1988). This drawback can modify by using such other systems like bundled-tube or braced-tube systems. One of the best known ways to decrease the shear lag is applying the diagonal members in the perimeter frame. Using this multi-story bracing leads to structure behave more like a hollow tube in bending mode as well as cause to increase the strength and stiffness of the frame-tube structures. Multi-story bracing term indicates to a brace that cover multi bay and multi story as the one for example $X$ bracing (Zahiri Hashemi 2008). This overall bracing can affect the structural response parameters such as, lateral displacement, seismic behavior and shear lag, etc. The main question is that how many overall bracing should be chosen for a tubular frame that takes more structural efficiency (Kheyroddin, Zahiri Hashemi 2008).

\section{Modeling and analysis}

In the current study, a residential steel frame with 20 stories has been considered as shown in Fig. 12. The typical buildings have 4 bays in both $\mathrm{X}$ and $\mathrm{Y}$

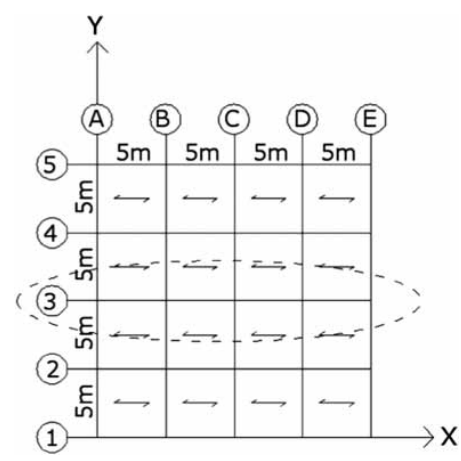

Fig. 12. Plan of the models 

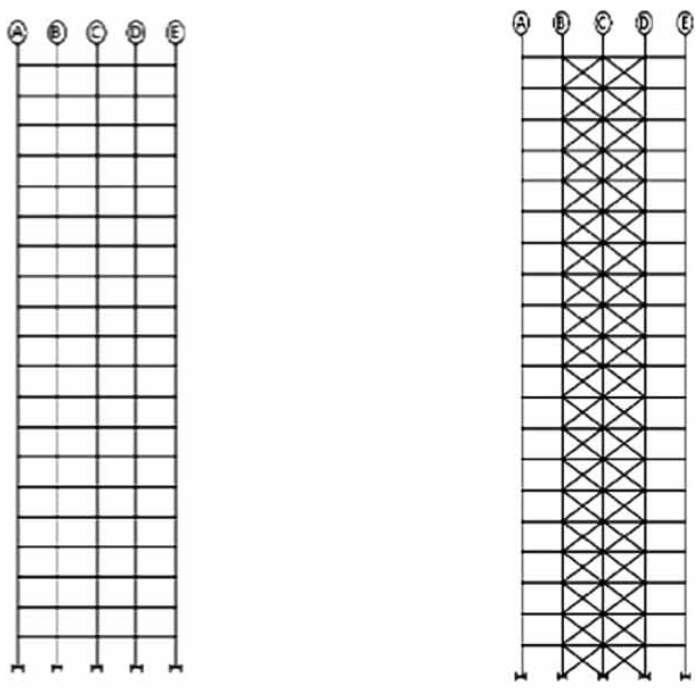

$\mathrm{a}-\mathrm{F} 20$

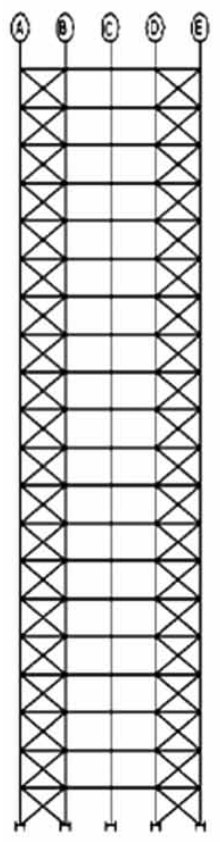

c- BFS20
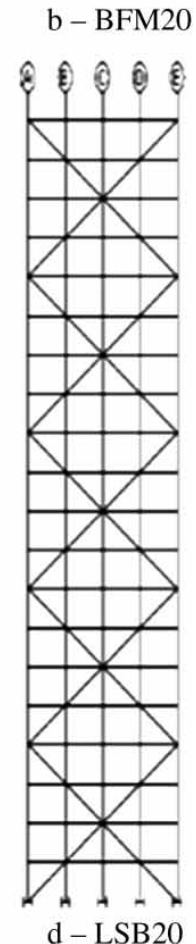

Fig. 13. Analytical models

directions. The height of the stories is constant and equal to $3 \mathrm{~m}$. Story masses are calculated using dead load plus $20 \%$ of live load. The models are assumed to be located on soil type II and very high seismic relative hazard for site region with design base acceleration $(\mathrm{PGA}=0.35 \mathrm{~g})$ of the Iranian No. 2800 Standard for Seismic Resistant Design of Buildings (BHRC 2005). The structural members have been designed according to the AISC requirements (AISC 2005). The uniform gravity loads have been considered as $700 \mathrm{~kg} / \mathrm{m}^{2}$ for all stories. The lateral loads have been determined in accordance to the Iranian No. 2800 Standard for Seismic Resistant Design of Buildings. Lateral resisting system of these buildings is conventional braced frame. The considered models assumed to have

Table 1. Name of models

\begin{tabular}{ll}
\hline Model & \multicolumn{1}{c}{ Description } \\
\hline F20 & $\begin{array}{l}\text { 20-story moment resisting frame with intermediate } \\
\text { ductility }\end{array}$ \\
BFM20 & 20-story braced frame with intermediate ductility \\
BFS20 & 20-story braced frame with intermediate ductility \\
LSB20 & 20-story large scale braced frame
\end{tabular}

intermediate ductility behavior. Ceiling system is considered as one-way slab.

For linear and nonlinear static analyses, computer program SAP 2000 version 9.1 was used to predict the model responses. The Rayleigh damping is adopted with a constant damping ratio of 0.05 . For studying the various types and arrangement of bracing in this 20-story structure, some models are selected below:

- F20: 20-story moment resisting frame with intermediate ductility which is shown in Fig. 13a;

- BFM20: 20-story braced frame with intermediate ductility which is shown in Fig. 13b. In this model, the bracings are at two middle bays of the frame and in the one story-height, bay-width modules;

- BFS20: 20-story braced frame with intermediate ductility which is shown in Fig. 13c. In this model, the bracings are at two side bays of the frame and in the one story-height, bay-width modules;

- LSB20: 20-story large scale braced frame which is shown in Fig. 13d. In this model, the bracings extend over 4 stories in all bays. In this model the diagonals and intermediate columns are connected together. These models are identified in Table 1.

For comparing these structures, one frame of these buildings (No. 3) is selected and all of the analyses are performed on these frames which are shown in Fig. 13. Linear and nonlinear static analyses are performed and the results presented in the next section.

At the first stage, F20 and BFS20 models are analyzed and designed in accordance with above mention codes. Hence, beam, columns and braces are designed and their profiles identified. At the second stage, BFM20 and LSB20 models are considered and all of their members are selected the same as the BFS20 model. In the other hand, the beam, column and brace cross sections are identical in each story and all of the models. In this stage, BFM20 and LSB20 models are not designed and their structural members are considered in accordance with BFS20 model. 


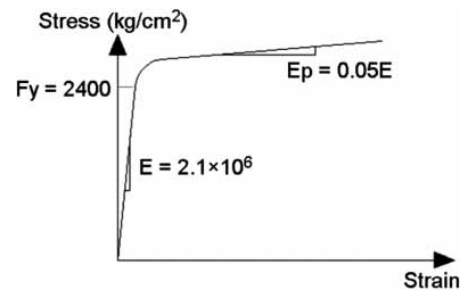

Fig. 14. Stress-strain curve for steel material (Asgarian, Jalilifar 2011)

Then these results are compared to each other and the related curves presented. At the $3^{\text {rd }}$ stage, BFM20 and LSB20 models with these cross sections are designed and the stress ratios of the structural members calculated and compared to the same values related to BFS20 model To model the St-37 steel behavior, stress-strain curve is used which is shown in Fig. 14. Beams in braced frames are modeled as moment-released beams at both ends. Therefore, beams are not parts of lateral resisting system and will behave elastically under gravity loads. Columns in braced frames are parts of a lateral resisting system and are supposed to enter nonlinear region in severe earthquakes. Hence, both geometric and material nonlinearity should be taken into account for them. Braces are modeled as moment-released elements at both ends and are supposed to behave as axial members. Geometric nonlinearity is provided in the same way as columns (Asgarian, Jalilifar 2011).

All of the models are analyzed by linear static and nonlinear static (push-over) methods. A nonlinear static analysis, also known as a push-over analysis, consists of laterally pushing the structure in one direction with a certain lateral force or displacement distribution until either a specified drift is attained or a numerical instability has occurred (FEMA 2000). The capacity curves are obtained by performing a series of three dimensional analyses on the building when it is subjected to a set of forces applied at the center of mass of the floors of the building. To obtain the capacity curves, a triangular distribution of horizontal loads applied to the whole models. This pattern of lateral loading is similar to the static seismic load distribution which is calculated for designing of these structures (Moghaddam, Tso 2000).

\section{Results and discussion}

\subsection{Lateral displacement}

The lateral displacement of BFS20, LSB20 and BFM20 are shown in Fig. 15. As shown in this figure, BFS20 and BFM20 models are very close to each other and the maximum difference is only about $2 \%$. The lateral displacement of LSB20 model is different and the maximum difference between BFS20 and LSB20 is about $45 \%$. This maximum difference is occurred at the roof story. As shown in this figure,

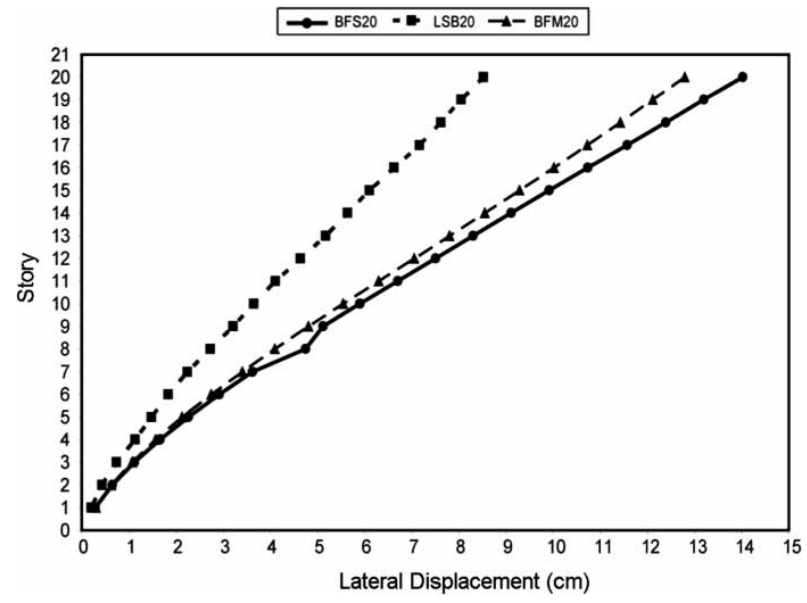

Fig. 15. Lateral displacement of different models

using LSB system causes that, the stiffness of the structure increases significantly and the lateral displacement decreases about $45 \%$ in compared with BFS20.

\subsection{Drift ratio}

The dimensionless parameter of $\frac{\Delta_{\text {story }}}{h_{\text {storv }}}$ is called drift ratio, where $\Delta_{\text {story }}$ is relative lateral displacement of each story due to lateral loading $\left(\Delta_{\text {story }}=\Delta_{T O P}\right.$ $\left.-\Delta_{B O T}\right)$ and $h_{\text {story }}$ is height of story.

The drifts of the mentioned models are presented in Fig. 16. The maximum drift belongs to BFS20 model. LSB model has the minimum drift ratio. As shown in this figure, the drift ratio of LSB20 model has a variable behavior and the maximum drift occurred at $17^{\text {th }}$ story. Using LSB system causes that, the stiffness of the structure increases significantly and the drift ratio decreases about $55 \%$ in compared with BFS20 at $17^{\text {th }}$ story.

\subsection{Story shear absorption percent}

As shown in previous sections, the BFS20 and BFM20 models behave very close to each other and hence, the

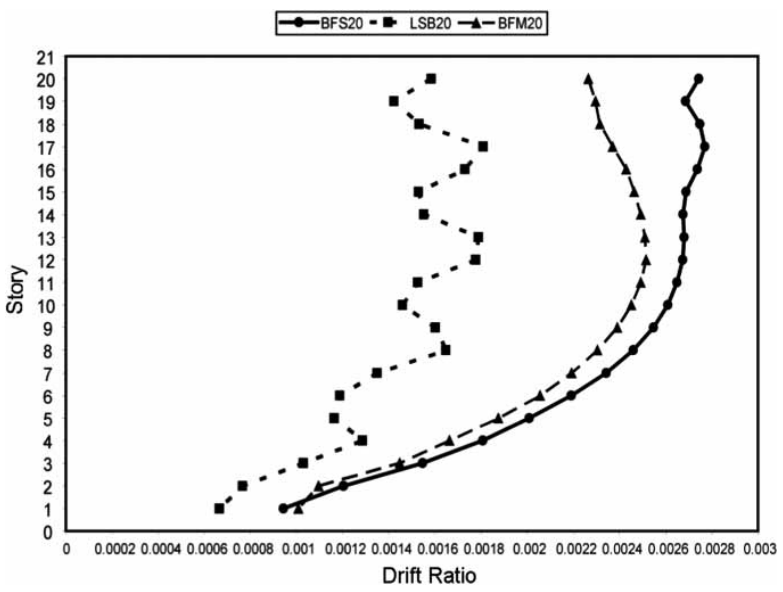

Fig. 16. Drift ratio of different models 


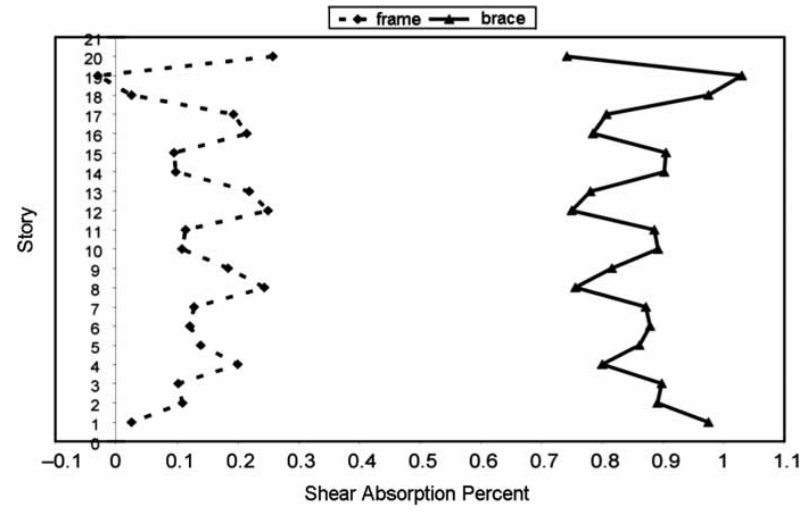

Fig. 17. Shear absorption percent of frame and brace systems in LSB20 model

results are presented only for BFS20 model. Horizontal forces which are applied over the height of the structures and at center of mass of the each floor, absorbed by the frames and braces of each story and divided between these structural members. Story forces applied at each floor horizontally and calculated in accordance with related codes. At each story, the summation of these horizontal forces which are located above this level, called "story shear".

As shown in previous sections, BFS20 and BFM20 models are similar to each other approximately. Hence, in this section only BFS20 and LSB20 are compared. In each story of LSB20 model, two dimensionless parameters of $\frac{V_{\text {Buree }}}{V_{\text {Serv }}}$ and $\frac{V_{\text {Frame }}}{V_{\text {STlov }}}$ are calculated and presented in Fig. 17. These two parameters are called "shear absorption percent", where $V_{\text {Brace }}$ is story shear which is absorbed by braces; $V_{\text {Story }}$ is shear story and $V_{\text {Frame }}$ is story shear which is absorbed by frames.

The summation of these two parameters must be 1 at each level. As observed bracing system absorbs more shear force than frame and the minimum is about $70 \%$ and it occurs at $20^{\text {th }}$ story. The frame absorbs at the maximum level only about $30 \%$ at $20^{\text {th }}$ story too. The variable behavior is observed in LSB20 model. This behavior is observed in Fig. 16, too. As shown in this figure, this type of bracing is very effective and absorbs at minimum $70 \%$ of the total story shear.

Story shear which is absorbed by frame and bracing system in BFS20 model is presented in Fig. 18. As shown in this figure, bracing system absorbs about $100 \%$ of story shear at first story and this trend decreases to about $50 \%$ at $10^{\text {th }}$ story. The minimum of this value is about $15 \%$ at $20^{\text {th }}$ story. The rest of the story shear is absorbed by frame system at each level. It is obvious that bracing system is more effective in lower stories and frame system is more efficient in upper stories of BFS20 model.

The frame shear absorption of BFS20 and LSB20 models are compared to each other and presented in Fig. 19. As shown in this figure,

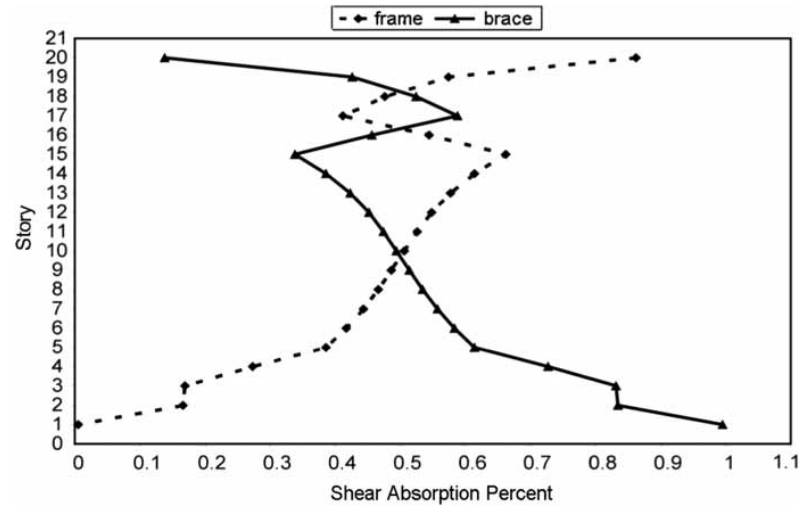

Fig. 18. Shear absorption percent of frame and brace systems in BFS20 model

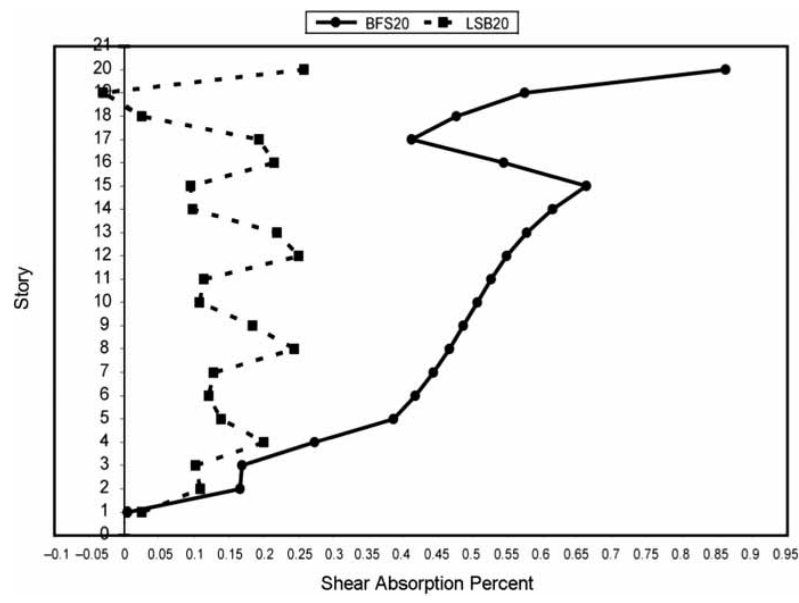

Fig. 19. Shear absorption percent of frame system in BFS20 and LSB20 models

the frame system in BFS20 is more effective than the frame system in LSB20 model in whole stories. The maximum difference occurs at $20^{\text {th }}$ story and is about $65 \%$. A sudden variation is shown in BFS20 model at $16^{\text {th }}$ story. This variation is due to changing in cross sections of the structural members in this level. Smaller variations are shown at $3^{\text {rd }}$ and $6^{\text {th }}$ stories for the same reason, too.

The brace shear absorption of BFS20 and LSB20 models are compared to each other and presented in Fig. 20. The brace system in LSB20 is more effective than the frame system in BFS20 model in whole stories. The maximum difference occurs at $20^{\text {th }}$ story and is about $80 \%$. A sudden variation is shown in BFS20 model at $16^{\text {th }}$ story. This variation is due to changing in cross sections of the structural members in this level. Smaller variations are shown at $3^{\text {rd }}$ and $6^{\text {th }}$ stories for the same reason too.

Hence, LSB system is more effective than other types of bracing systems that were discussed in previous sections. 


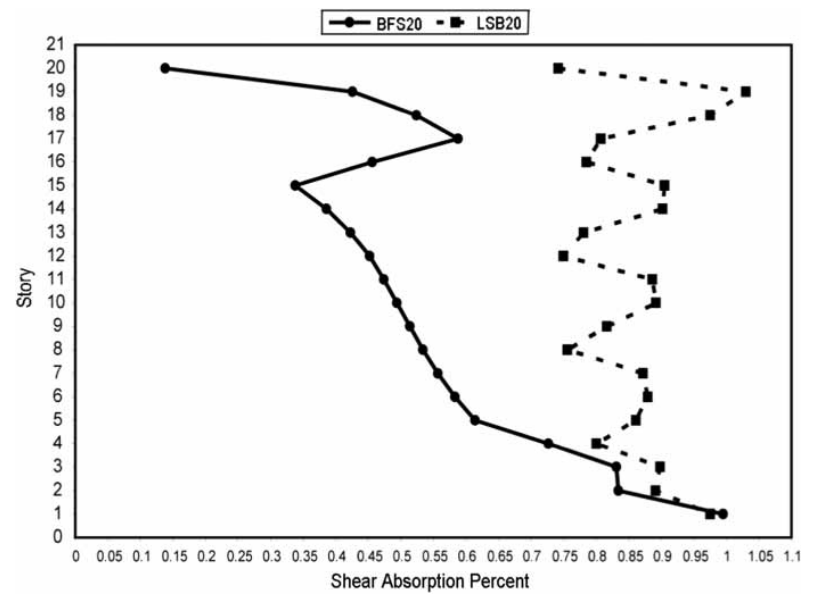

Fig. 20. Shear absorption percent of brace system in BFS20 and LSB20 models

\subsection{Economical investigation}

The whole beams, columns and braces are assumed to be identical in the whole models in previous sections. On the other hand the profiles which are used for these models are identical and have the same area, weight and other specifications. Hence, BFM20 and LSB20 are designed with the same cross sections and stress ratios of the structural members are calculated. On the other hand, these ratios could be used for economical comparisons. As the stress ratios in structural members are less, the capacity of the each member and the whole structure will increase. Therefore, smaller cross sections and members could be used for the building to achieve the same capacity curve. As shown in previous sections, the BFS20 and BFM20 models behave very close to each other and hence, the results are presented only for BFS20 model.

Stress ratio is a dimensionless parameter which is identified as $\frac{\sigma}{\sigma_{a l}}$, where $\sigma$ is calculated stress in each structural member and $\sigma_{a l}$ is allowable stress according to design codes. Summation of the stress ratios in the columns of two models in each story are presented in Fig. 21. As shown, these ratios in BFS20 are more than LSB20 model. Hence, LSB20 model is more economical and the maximum difference between these models is about $45 \%$ and occurred in $5^{\text {th }}$ to $15^{\text {th }}$ levels. There are some points in these 2 curves that the trend has local irregularity. In these points the cross sections of models are changed.

Summation of the stress ratios in the beams of two models in each story are presented in Fig. 22. As shown, these ratios in BFS20 are more than LSB20 models. Hence, LSB20 model is more economical and the maximum difference between these models is about $55 \%$ and occurred in $7^{\text {th }}$ to $20^{\text {th }}$ levels. There are some points in these curves that the trend has local irregularity. In these points $\left(3^{\text {rd }}, 6^{\text {th }}\right.$ and $16^{\text {th }}$ stories) the cross sections of the models are changed.

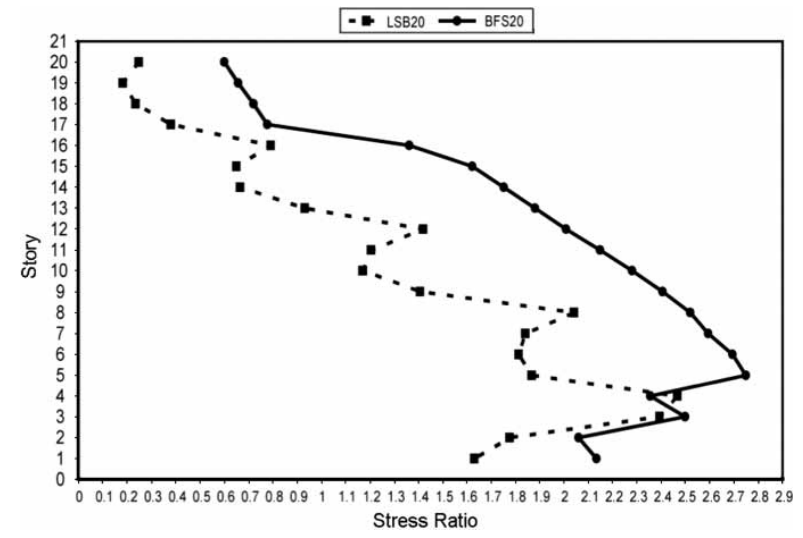

Fig. 21. Summation of the stress ratios in the columns of all models in each story

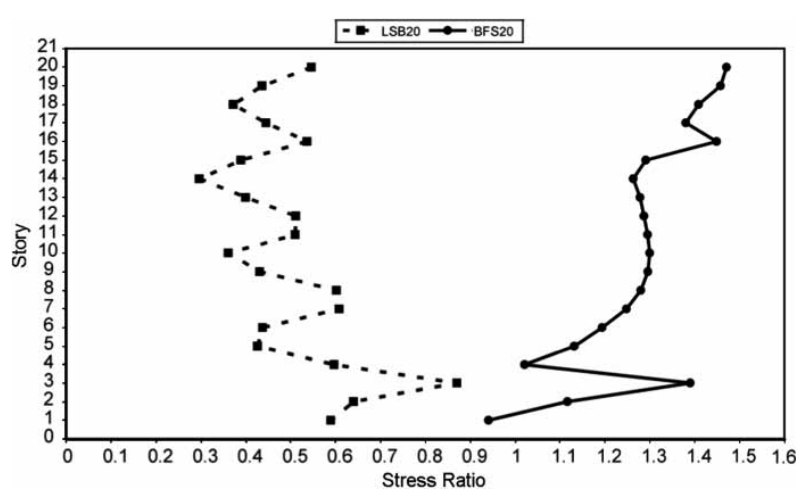

Fig. 22. Summation of the stress ratios in the beams of all models in each story

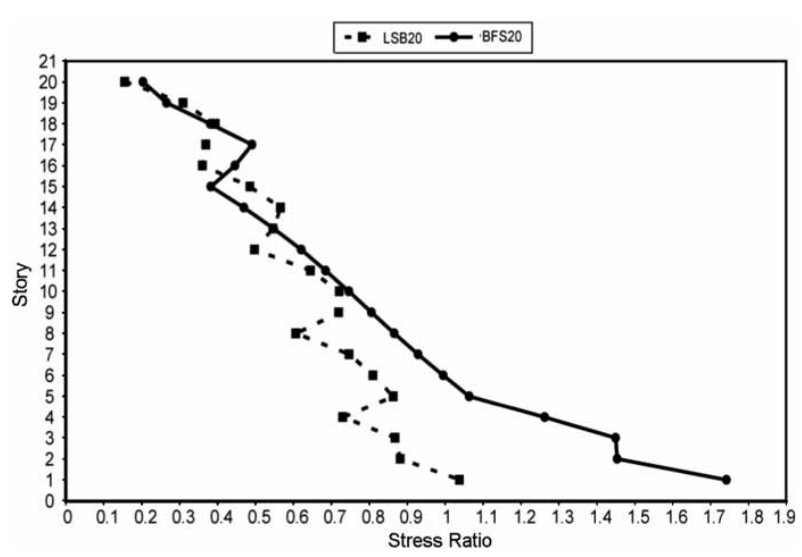

Fig. 23. Summation of the stress ratios in the braces of all models in each story

Summation of the stress ratios in the braces of all models in each story are presented in Fig. 23. As shown, BFS20 and LSB20 models are close to each other approximately, especially at story 10 to story 20 . At the lower stories, the effectiveness of bracing system in BFS20 model is more than LSB20 model and hence, the stress ratios in braces of BFS20 model are more than LSB20. The maximum difference between these two models is about $45 \%$ and is 


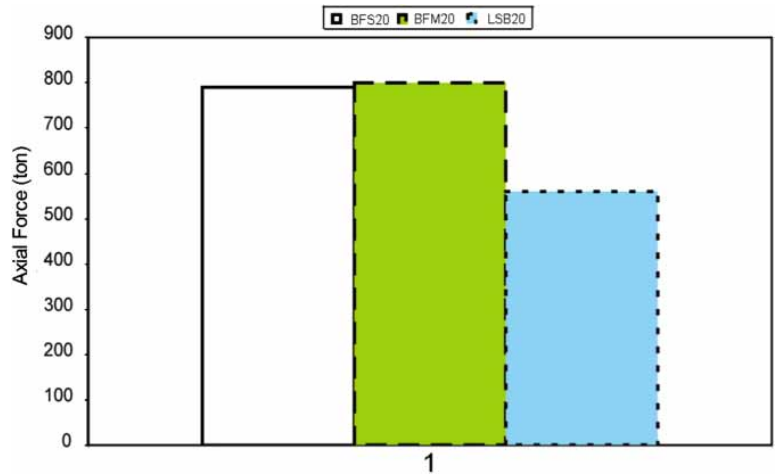

Fig. 24. Summations of uplifts in the whole models

occurred in $1^{\text {st }}$ story. There are some points in these curves that the trend has local irregularity. In these points the cross sections of models are changed. As shown in this figure, LSB20 model has less stress ratios and hence, is more economical than other models.

\subsection{Axial tensile force in foundations (uplift)}

Tension forces which are produced in foundations during an earthquake are called uplift. It is very dangerous for the structures and must be avoided or minimized (Ayvaz, Çavdar 2007). These forces are produced in braced bays because of high stiffness of these bays. In these foundations, tension forces which are produced due to lateral loads exceed the compression forces produced due to gravity loads and the resultant upward force is called uplift. Summation of uplifts in the whole foundations of each model is presented in Fig. 24. As shown in this figure, LSB model has the minimum tensile forces. The difference is about $30 \%$ among these models.

\subsection{Push-over analysis}

A nonlinear static analysis, also known as a push-over analysis, consists of laterally pushing the structure in one direction with a certain lateral force or displacement distribution until either a specified drift is attained or a numerical instability has occurred (Colajanni, Potenzone 2008). Capacity curves of the different models, which are obtained from push-over analysis, are presented in Fig. 25. As shown, largescale bracing (LSB20) has the maximum ultimate load and the difference is about $15 \%$ in compared with other models. There is a fast drop in this model after the linear behavior. This drop decreases the capacity of the structure about $55 \%$.

This phenomenon could be because of low number of braces in this model. But, after this stage, LSB20 model behaves like BFS20 and BFM20 models. As shown in Fig. 25, the initial stiffness of LSB20 is about $20 \%$ more than other models and hence, it seems that, the smaller lateral displacement due to

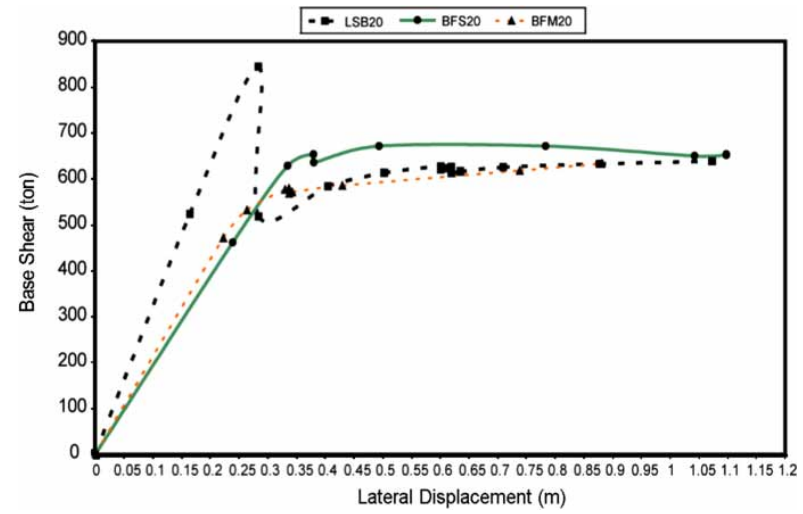

Fig. 25. Capacity curves of the different models

lateral loads and effectiveness of the braces are the results of this high stiffness. This high stiffness is distributed in the whole members of the LSB20 model and then, the tension forces in foundations of this structure decrease. The ultimate deformation of LSB20 and BFS20 are very close to each other. The ductility factor $(\mu)$ of the LSB20 is more than BFS20. The difference is about $15 \%$. Ductility factor is the proportion of yield deformation to ultimate deformation.

As shown in Figs 12 and 13, the aspect ratio of these models is equal to $(60 \mathrm{~m} / 20 \mathrm{~m})=3$. In this definition, $60 \mathrm{~m}$ and $20 \mathrm{~m}$ are the total height and width of these structures respectively. Hence, these models could be categorized in the range of tall buildings (Stafford Smith, Coull 1991). It is obvious that previous results which have been presented in this paper allocated to the models shown in Figs 12 and 13 and for achieving more precise results, more analyses and stochastic evaluation methods must be adopted.

\section{Conclusions}

The typical arrangement of bracing in tall buildings is in story height, bay width modules. In this form, it is usually possible to conceal the bracing within the walls or façade of building to leave little evidence of its being a braced structure. Effectiveness of bracings in resisting lateral loading systems has been further exploited by using it on larger modular scale, both within the building and externally across the faces. In the latter form, the massive diagonals have sometimes been emphasized as an architectural feature of the façade. The role of the bracing is multi purpose in resisting the horizontal shear and hence making the whole cross section of the building structure stiffer against lateral load bending and helping to equalize the gravity load stresses in the column. LSB20 model (large-scale bracing) shows adequate response to the lateral loading. Lateral displacement, drift ratio and uplift of this model are less than other models. This model is more economic and the braces are more effective than others. BFS20 and BFM20 models are 
similar to each other approximately. Large-scale bracings have an adequate capacity curve too. This type of bracing could be used in steel structures for its excellent specifications.

\section{References}

AISC-LRFD: Load and Resistance Factor Design Specification for Steel Buildings. American Institute of Steal Constructions (AISC). Chicago, Illinois, 2005. 53 p.

Asgarian, B.; Jalaeefar, A. 2011. Incremental dynamic analysis of steel braced frames designed based on first second and third editions of the Iranian seismic code (standard no. 2800), The Structural Design of Tall and Special Buildings 20(2): 190-207. http://dx.doi.org/10.1002/tal.528

Ayvaz, Y.; Çavdar, O. 2007. Earthquake behavior of frame structures stiffened with $\mathrm{K}$ and Knee bracing members, in Proc. of the 5th International Conference on Seismology and Earthquake Engineering SEE5, Tehran, Iran, 2007. 7 p.

Building and Housing Research Center: Iranian Code for Seismic Resistant Design of Buildings. Iran, Tehran, 2005. 48 p.

Colajanni, P.; Potenzone, B. 2008. Influence of lateral load distributions on push-over analysis effectiveness, in AIP Conference Proceedings of the Seismic Engineering Conference, Commemorating the 1908 Messina and Reggio Calabria Earthquake, 2008, 1020: 880-887.

FEMA: Prestandard and Commentary for the Seismic Rehabilitation of Buildings. Federal Emergency Management Agency, Washington DC. 2000. 518 p.

Ji, T. 2003. Concepts for designing stiffer structures, The Structural Engineer 4 November, 2003, 36-42.

Kheyroddin, A.; Zahiri Hashemi, R. 2008. Investigation of the shear lag behavior in braced tubular structures, in Proc. of the CSCE Annual Conference, 10-13 June, 2008, Quebec City, Canada, 2008. 5 p.
Kim, J.; Lee, Y.-H. 2010. Progressive collapse resisting capacity of tube-type structures, The Structural Design of Tall and Special Buildings 19(7): 761-777.

Leonard, J. 2007. Investigation of shear lag effect in high-rise buildings with diagrid system. MSc thesis. Massachusetts: Massachusetts Institute of Technology, USA. 50 p.

Lu, X.; Zou, Y.; Lu, W.; Zhao, B. 2007. Shaking table model test on shanghai world financial center tower, Earthquake Engineering and Structural Dynamics 36: 439-457. http://dx.doi.org/10.1002/eqe.634

Mazzolani, F. M.; Della Corte, G.; D’Aniello, M. 2009. Experimental analysis of steel dissipative bracing systems for seismic upgrading, Journal of Civil Engineering and Management 15(1): 7-19. http://dx.doi.org/10.3846/1392-3730.2009.15.7-19

Moghaddam, A. S.; Tso, W. K. 2000. 3-D pushover analysis for damage assessment of buildings, Journal of Seismology and Earthquake Engineering 2(3): 23-31.

Moon, K. S. 2005. Dynamic interrelationship between technology and architecture in tall Buildings. $\mathrm{PhD}$ thesis. Massachusetts: Massachusetts Institute of Technology, USA. 230 p.

Stafford Smith, B.; Coull, A. 1991. Tall building structures: analysis and design. New York: John Wiley \& Sons. $537 \mathrm{p}$.

Tang, A. P.; Yin, H. P. 2007. Seismic response analysis of eccentrically braced steel frames, in Proc. of The 5th International Conference on Seismology and Earthquake Engineering SEE5, Tehran, Iran, 2007. 8 p.

Taranath, B. S. 1988. Structural analysis and design of tall buildings. New York: McGraw Hill. 672 p.

Taranath, B. S. 2005. Wind and earthquake resistant buildings, structural analysis and design. New York: Marcel Dekker. 912 p.

Zahiri Hashemi, R. 2008. Investigation of the seismic behavior of braced-tube system in tall buildings. MSc thesis. Semnan University, Iran. 70 p.

Ali HEMMATI. PhD candidate in the Civil Engineering Faculty at Semnan University. He is a member of ICI (Iranian Concrete Institute). His research interests include tall buildings, behavior of reinforced concrete structural elements, and application of H PFRCC in structures and nonlinear finite element analysis of structures.

Ali KHEYRODDIN. Professor in the Civil Engineering Faculty at Semnan University. He is a member of ICI (Iranian Concrete Institute). His research interests include tall buildings, seismic rehabilitation and nonlinear finite element analysis of reinforced concrete structures. 